\title{
O que a membrana tem?
}

What does the membrane have?

Ana Paula Fantecelle Junger ${ }^{1}$, Karina Carvalho Mancini ${ }^{2}$, Viviana Borges Corte ${ }^{3}$

${ }^{1}$ Programa de Pós-Graduação em Rede em Ensino de Biologia (PROFBIO), Universidade Federal do Espírito Santo, São Mateus, Espírito Santo, Brasil

${ }^{2}$ Universidade Federal do Espírito Santo, Departamento de Ciências Agrárias e Biológicas, São Mateus, Espírito Santo, Brasil.

${ }^{3}$ Universidade Federal do Espírito Santo, Departamento de Ciências Biológicas, Vitória, Espírito Santo, Brasil.

EEEFM Vila Nova de Colares

Rua B, 67, Praia da Baleia, CEP 29.172-684, Serra, Espírito Santo, Brasil

Tel: +55 27 99794-4901

Email: apjunger@hotmail.com

Submetido em 20/12/2020

Aceito em 21/12/2020 


\title{
RESUMO
}

O trabalho trata-se de uma proposta de atividade investigativa sobre o tema Citologia para as aulas de Biologia do ensino médio, tendo como objetivo investigar de que forma a constituição da membrana influencia na função de entrada e saída das substâncias, conhecendo as estruturas que formam o modelo de mosaico fluido e como estas estruturas estão dispostas ao longo das membranas. Assim, a proposta envolve a construção de membranas a partir de figuras em papel de seus componentes químicos. A atividade investigativa gera um maior interesse e reflexão, o que permite um entendimento dos conceitos básicos como também os termos que envolvem esse conteúdo.

Palavras-chave: Biologia. Citologia. Atividade Investigativa. Construção. Ensino.

\begin{abstract}
The work is a proposal for an investigative activity on the subject of Cytology for Biology classes in high school with the objective of investigating how the constitution of the membrane influences the function of entry and exit of substances, knowing the structures that form the fluid mosaic model and how these structures are arranged along the membranes. Thus, the proposal involves the construction of membranes from paper figures of their chemical components. The investigative activity generates greater interest and reflection, which allows an understanding of the basic concepts as well as the terms that involve this content.
\end{abstract}

Keywords: Biology. Cytology. Investigative Activity. Construction. Teaching.

Health and Biosciences, v.1, n.3, Dez. 2020

Disponível em: https://periodicos.ufes.br/healthandbiosciences 


\section{INTRODUÇÃO}

O estudo da Biologia, assim como o de outras disciplinas, é feito tradicionalmente por memorização e por meio da fragmentação dos conteúdos (SELLES \& FERREIRA, 2005). Deve-se considerar que tais métodos se refletem na falta de motivação do aluno a qual é uma variável extremamente relevante do processo ensino-aprendizagem (POZO \& CRESPO, 2009). Nesse sentido, é de suma importância a utilização de diferentes métodos e estratégias de ensino que fomentem uma atitude reflexiva por parte do aluno, na medida em que oferecem oportunidades de participação, vivência de uma variedade de experiências, tomada de decisões, julgamentos e conclusões (BENETTI, 2002).

Orlando e colaboradores (2009) destacam que dentro da Biologia os conteúdos relacionados às áreas de Bioquímica, Biologia Celular e Molecular são os que mais exigem elaboração de material didático de apoio ao livro didático, visto que sua abordagem emprega conceitos muito abstratos e trabalha com aspectos microscópicos.

Uma forma de tentar reverter esse quadro de desmotivação dentro de conteúdos muito abstratos na Biologia é a utilização de uma abordagem investigativa. Esta tem sido apontada como uma importante estratégia de ensino para o aumento da participação dos alunos (GOI \& SANTOS, 2008). Atividades que utilizam essa abordagem se mostram motivadoras e estão diretamente relacionadas ao ganho de diversas habilidades como o desenvolvimento do raciocínio, do pensamento crítico, formulação de hipóteses, elaboração de um plano de trabalho, montagem de aparato experimental, coleta de dados, discussão consigo e/ou com outros alunos, entre outras (LABURU, 2011).

Diante do exposto, esse trabalho apresenta um recurso didático simples, de fácil produção e que se propõe a explicar os conteúdos referentes à constituição da membrana plasmática por meio de uma atividade investigativa, além de facilitar a compreensão do assunto, envolvendo mais os alunos no processo de construção do seu conhecimento.

\section{OBJETIVOS}

$\checkmark$ Investigar de que forma a constituição da membrana influencia na função de entrada e saída das substâncias.

$\checkmark$ Conhecer as estruturas que formam o modelo de mosaico fluido das membranas.

Health and Biosciences, v.1, n.3, Dez. 2020

Disponível em: https://periodicos.ufes.br/healthandbiosciences 
$\checkmark$ Entender como as estruturas estão dispostas ao longo da membrana.

\section{METODOLOGIA}

\section{Materiais utilizados}

- Ilustrações das moléculas componentes da membrana plasmática (Figura 1) nas seguintes quantidades: 80 fosfolipídios, 5 proteínas periféricas, 5 carboidratos e 6 proteínas transmembranas (duas de cada tipo). É o suficiente para os alunos construírem uma membrana completa em uma folha de tamanho A4;

- Envelopes para colocar as imagens das moléculas (um para cada grupo formado);

- Folhas sulfite de tamanho A4 para os alunos construírem a membrana em cima (uma por grupo).



Figura 1. Ilustrações das moléculas que compõem a membrana plasmática. AFosfolipídios; B- Carboidrato; C- Proteínas transmembranas; D- Proteína periférica. Fonte: ALBERTS et al., 2017.

Caso o docente queira abordar fluidez de membrana, é necessário que as ilustrações destaquem fosfolipídios com caudas curtas e longas, insaturadas e saturadas. 


\section{Desenvolvimento}

São necessárias 2 aulas para desenvolver essa atividade. Na primeira aula projete ou leve imagens de células eucariontes, procariontes e organelas. Em todas essas imagens a membrana é uma linha e com essa percepção faça uma discussão sobre delimitação das células e compartimentos intracelulares. É interessante complementar a conversa sobre membranas com a utilização de um material tridimensional, como um balão grande cheio, representando a célula, e pequenos balões cheios dentro, como se fossem organelas, e a partir disso explicar que os meios externo e interno possuem água e que de alguma forma a membrana impede a sua entrada e saída excessiva. Leve para essa discussão exemplos de interação da célula com o meio externo e exemplos reais de transporte de diferentes substâncias. E em meio a discussão pergunte aos alunos: Por que algumas substâncias passam mais facilmente pela membrana que outras? Que substâncias formam as membranas de forma a permitir esse fato? A organização dessas substâncias influencia nas suas funções? Peça que os alunos registrem essas respostas e te entreguem.

Para finalizar a aula, divida os alunos em grupos e peça que eles pesquisem a história das biomembranas em casa, enfatizando os diferentes experimentos que foram feitos até chegarem ao modelo mais atual e levem os resultados na aula seguinte.

Na segunda aula, cada grupo deverá falar de forma breve o que foi achado durante as pesquisas e o professor deverá ir montando no quadro a ordem cronológica de cada acontecimento histórico relatado pelos alunos.

Em seguida, divida a turma em grupos de 4 a 5 alunos e distribua os envelopes com as imagens das moléculas que formam a membrana (Figura 1) e as folhas sulfite para que ocorra sua montagem como demonstra a Figura 2.

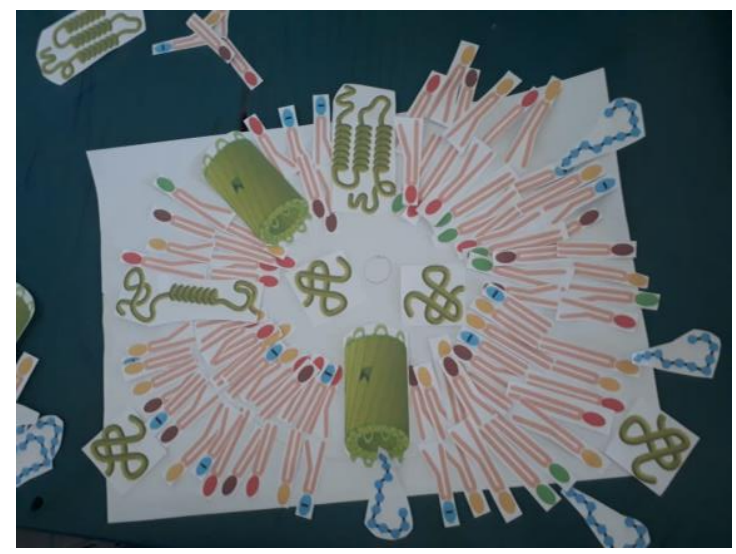

Figura 2. Membrana plasmática montada por alunos.

Health and Biosciences, v.1, n.3, Dez. 2020

Disponível em: https://periodicos.ufes.br/healthandbiosciences 
Junto com as imagens forneça o seguinte texto base que servirá como guia para a montagem da membrana.

\begin{abstract}
"Modelo Mosaico Fluido
A membrana é formada por uma bicamada (duas camadas) fosfolipídica onde as proteínas se distribuem de lado a lado como se fossem pessoas em uma multidão. Os fosfolipídios que formam a membrana apresentam duas regiões distintas: uma cabeça polar (hidrofílica) e uma cauda apolar (hidrofóbica). Eles organizam-se de modo que sua cabeça fique voltada para a superfície aquosa e as caudas para o interior da dupla camada. As proteínas podem estar dispostas superficialmente ou então atravessando totalmente a membrana. Quando as proteínas estão dentro da bicamada lipídica, são chamadas de integrais. Quando as proteínas se estendem através de toda a camada fosfolipídica (de um lado a outro), recebem o nome de proteínas transmembranas. Existem ainda aquelas que ficam inteiramente fora da membrana, são as chamadas periféricas. Externamente à membrana, encontramos os glicídios ou carboidratos. Eles podem estar ligados aos lipídios (glicolipídio) ou às proteínas (glicoproteínas). Elas formam o chamado glicocálix.” (SANTOS, 2019).
\end{abstract}

Depois que os grupos terminarem deverão explicar a escolha das imagens e a posição em que foram colocadas. Peça que os estudantes comparem a membrana plasmática montada pelo grupo com suas impressões iniciais individuais (hipóteses) entregues na primeira aula. Caso seja necessário faça correções nas membranas montadas pelos alunos, mas sempre levando o aluno a pensar no porquê dessas alterações.

\title{
PONTOS INVESTIGATIVOS DA ATIVIDADE
}

Segundo Bell e colaboradores (2005) a atividade investigativa pode ser categorizada de acordo com o nível de investigação que ela suporta. Dessa forma, entende-se que essa atividade investigativa se encontra no nível dois, pois os alunos investigam uma resposta para a questão colocada pelo professor, sendo-lhes dado o procedimento.

\section{CONSIDERAÇÕES}

A aula tradicional apenas expositiva costuma ser desmotivante para os estudantes prejudicando seu aprendizado. Como alternativa temos a abordagem investigativa onde o aluno constrói seu próprio aprendizado, raciocinando, refletindo e relacionando com seu cotidiano. Essa aula investigativa sobre membrana plasmática tem um resultado satisfatório, pois gera um maior interesse e reflexão por parte dos alunos, o que permite um entendimento dos conceitos básicos como também os termos que envolvem esse conteúdo.

Health and Biosciences, v.1, n.3, Dez. 2020

Disponível em: https://periodicos.ufes.br/healthandbiosciences 
Para isso é importante que alguns quesitos sejam trabalhados de forma adequada. É necessário, por exemplo, que a aula se inicie de forma contextualizada e que o texto base tenha termos mais simples ou que já tenham sido trabalhados nas aulas de bioquímica anteriormente. Para tratar sobre a contextualização desse tema é indicado que o docente leia o artigo "Once upon a time the cell membranes: 175 years of cell boundary research" (LOMBARD, 2014), pois esse artigo traz um detalhado histórico sobre a descoberta da membrana e vários trechos podem ser utilizados na segunda aula.

É imprescindível que o professor esclareça as dúvidas na hora da montagem, pois os alunos, em geral, demonstram dificuldades na assimilação com tantos termos novos. Entretanto, é importante que esse auxílio seja feito sem que as respostas sejam fornecidas, de forma que o aluno consiga refletir chegando a sua própria conclusão.

\section{AGRADECIMENTOS}

O presente trabalho foi realizado com o apoio da Coordenação de Aperfeiçoamento de Pessoal de Nível Superior - Brasil (CAPES) - Código de financiamento 001.

\section{REFERÊNCIAS BIBLIOGRÁFICAS}

\section{ALBERTS B, JOHNSON A, LEWIS J, MORGAN D, RAFF M, ROBERTS K, WALTER}

P, WILSON J, HUNT T. Biologia molecular da célula, 6.ed., Porto Alegre: Artmed, 2017, $1464 p$.

2. BELL RL, SMETANA L, BINNS IC. Simplifying inquiry instruction. Sci teacher 7(72): 30$33,2005$.

3. BENETTI, B. A temática ambiental e os procedimentos didáticos: perspectivas de professores de Ciências. In: VIII Encontro Perspectivas do Ensino de Biologia, 6, 2002, São Paulo. Anais, São Paulo: FEUSP, 2002.

4. GOI MEJ, SANTOS FMT. Resolução de problemas e atividades experimentais no ensino de química. 2008. In: XIV Encontro nacional de ensino de química, Curitiba, 2008. 
5. LABURU CE, BARROS MA, KANBACH BG. A relação com o saber profissional do professor de física e o fracasso da implementação de atividades experimentais no ensino médio. Ienci 12(3): 305-320, 2007.

6. LOMBARD J. Once upon a time the cell membranes: 175 years of cell boundary research. Biol Direct 9(32): 1-35, 2014.

7. ORLANDO TC, LIMA AR, SILVA AM, FUZISSAKI CN, RAMOS CL, MACHADO D, FERNANDES FF, LORENZI JCC, LIMA MA, GARDIM S, BARBOSA VC, TRÉS TA. Planejamento, montagem e aplicação de modelos didáticos para abordagem de Biologia Celular e Molecular no Ensino Médio por graduandos de Ciências Biológicas. Rev Bras Ens Bioquim e Biol Molecular 1: 1-17, 2009.

8. POZO JI, CRESPO MAG. A aprendizagem e o ensino de ciências. Porto Alegre: Artmed, 2009, 296p.

9. SANTOS VS. O que é o modelo do mosaico fluido? Brasil Escola, 2019. Disponível em: https://brasilescola.uol.com.br/o-que-e/biologia/o-que-e-modelo-mosaico-fluido.htm. Acesso em 20 de outubro de 2019.

10. SELLES SE, FERREIRA MS. Disciplina escolar Biologia: entre a retórica unificadora e as questões sociais. In: Marandino M, Selles S, Ferreira MS, Amorim AC editores. Ensino de Biologia: conhecimentos e valores em disputa, Niterói: Eduff, p.50-62, 2005.

Health and Biosciences, v.1, n.3, Dez. 2020

Disponível em: https://periodicos.ufes.br/healthandbiosciences 